\title{
Research on strategies of safety evacuation simulation in the urban public space based on virtual simulation technology
}

\author{
Feng $\mathrm{Yao}^{1,2, a *}$, Yang Jieying ${ }^{1,2, b}$, Li Guanghao ${ }^{1,2, c}$, Zhu Bingmiao ${ }^{3, d}$ \\ ${ }^{1}$ School of Architecture of Harbin Institute of Technology, Xidazhi Street 66\#,Nangang District, \\ Harbin, Heilongjiang Province150006, China \\ ${ }^{2}$ Institute of Landscape and Ecological Planning of Architecture, Harbin Institute of Technology, \\ Xidazhi Street 66\#,Nangang District, Harbin, Heilongjiang Province150006, China \\ ${ }^{3}$ The College of Landscape, Northeast forestry University, Hexing Road 26\#, Xiangfang District, \\ Harbin, China

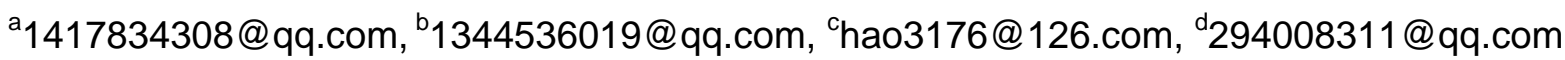 \\ * Corresponding author. E-mail address: 1417834308@qq.com
}

Keywords: safety evacuation, virtual simulation, urban public space, Cellular Automaton, Building Exodus

\begin{abstract}
In reference to domestic and international research on the theories and software of emergency evacuation, this paper aims at creating an emergency evacuation model of urban public space based on the Building Exodus, and the improved theory of Cellular Automaton (CA) was employed as the theoretical basis of the model. Harbin Children's Park of China is selected as a shelter to simulate evacuation, which is based on virtual simulation technology. According to analysis of the results of the simulation, this study provided strategies of safety evacuation in Harbin Children's Park and the region of its disaster prevention.
\end{abstract}

\section{Introduction}

Recently, there are various unexpected emergencies in the urban area. These emergencies caused great damages to people's lives and health on the worldwide scale, including emergencies caused by extreme natural disasters, such as the 2004 Indian Ocean earthquake and tsunami, the 2008 Sichuan earthquake, the 2011 Tohoku earthquake and tsunami, etc. And there are also emergencies resulting from improper management measures, such as the 911 terrorist attacks, the 2004 Beijing Lantern Festival stampede, the 2014 shoe factory fire in China, the 2014 Shanghai stampede, the 2015 Tianjin warehouse explosion and so on.

In response to these severe disasters, some relevant domestic departments announced Law of the People's Republic of China on Protecting Against and Mitigating Earthquake Disasters, Regulation on the Relief of Natural Disasters, Emergency Response Law of the People's Republic of China and other related laws and regulations. It includes the construction of virtual simulation systems to prevent severe natural disaster in some major projects planning of National Comprehensive Plan of Disaster Prevention and Mitigation(2011-2015) of China. Consequently, the research of emergency evacuation in emergency situations is urgent.

There are also some comprehensive management measures against emergencies in foreign countries. According to the classification of White Paper on Disaster Management, Japan established the legal systems of Japanese disaster prevention and mitigation which is constituted by 52 legislations, including Disaster Countermeasures Basic Act, Disaster Relief Act and so on. In addition, many countries paid lots of attentions to treatments of emergencies, such as Federal Emergency Response Plan and Disaster Relief Bill in America, Australia Crisis Management Act and National Emergency Management in Australia, Canada crisis preparedness law and Crisis law in Canada, etc. 
Harbin is a critical disaster prevention city in China. Although there is a comprehensive prevention system against disasters in Harbin, it is also one of the significant issues that how people in the centre urban area can safely get to the planned shelters in the shortest time.

\section{Research on model of emergency evacuation}

\subsection{The theory of emergency evacuation}

To sum up the literature of emergency evacuation, this paper lists some main theories which are widely used recently as follows in table 1 .

Table 1 The main theory of emergency evacuation

\begin{tabular}{lcccc}
\hline Related Theory & $\begin{array}{l}\text { Time of } \\
\text { release in the } \\
\text { first time }\end{array}$ & $\begin{array}{l}\text { Time of theory } \\
\text { applied in } \\
\text { evacuation }\end{array}$ & $\begin{array}{l}\text { Time of } \\
\text { Latest Update }\end{array}$ & $\begin{array}{l}\text { Quantities of } \\
\text { articles related } \\
\text { with evacuation }\end{array}$ \\
\hline $\begin{array}{l}\text { The Fuzzy theory } \\
\text { The Queuing theory }\end{array}$ & 1980 & 2006 & 2014 & 8 \\
$\begin{array}{l}\text { The Shortest Path Theory } \\
\text { The optimality theory }\end{array}$ & 1964 & 2006 & 2013 & 9 \\
$\begin{array}{l}\text { The Cluster flow theory } \\
\text { The Population dynamics }\end{array}$ & 1979 & 2011 & 2012 & 2 \\
$\begin{array}{l}\text { theory } \\
\text { The Cellular automata }\end{array}$ & 2004 & 2001 & 2015 & 5 \\
theory & 1993 & 2008 & 2013 & 4 \\
The ACO theory & 2000 & 2004 & 2008 & 22 \\
\hline
\end{tabular}

Through summarizing the main theories, the Cellular Automata Theory(CA) is widely used in emergency evacuation recently. The theory is not only applied in prior research of emergency evacuation in the past years, but also the experts and scholars from different backgrounds are expanding this theory continually in recent years.

2.2 The software of emergency evacuation

In a traditional way, most of the software of emergency evacuation is applied inside the building, but in reference to evacuation discipline inside the building, and these disciplines which are now expected to be used in the urban public space. Evacuation software mainly applied in the subject of architecture are summarized as follows in table 2.

Table 2 Evacuation software mainly applied in the subject of architecture

\begin{tabular}{lcccccc}
\hline $\begin{array}{l}\text { Evacuation } \\
\text { software }\end{array}$ & $\begin{array}{l}\text { Time of } \\
\text { release } \\
\text { in the } \\
\text { first } \\
\text { time }\end{array}$ & $\begin{array}{l}\text { Quantit } \\
\text { ies of } \\
\text { articles } \\
\text { since } \\
2005\end{array}$ & $\begin{array}{l}\text { Proportion } \\
\text { of applied in } \\
\text { the subject } \\
\text { Architecture }\end{array}$ & $\begin{array}{l}\text { Proportion } \\
\text { of applied } \\
\text { in the } \\
\text { subject of } \\
\text { Security }\end{array}$ & $\begin{array}{l}\text { Quantities of } \\
\text { articles related } \\
\text { with software } \\
\text { in architecture } \\
\text { (2010-2015) }\end{array}$ & $\begin{array}{l}\text { Quantities of } \\
\text { articles related } \\
\text { with evacuation } \\
\text { software (2015) }\end{array}$ \\
\hline Evacnet4 & 1984 & 227 & $42.3 \%$ & $22.9 \%$ & 10 & 1 \\
Wayout & 1993 & 97 & $37.1 \%$ & $28.9 \%$ & 2 & 0 \\
Pathfinder & 1998 & 368 & $55.2 \%$ & $18.5 \%$ & 76 & 4 \\
Exitt & 1987 & 143 & $45.5 \%$ & $30.8 \%$ & 0 & 0 \\
Steps & 1989 & 41 & $61.0 \%$ & $17.1 \%$ & 6 & 1 \\
Simulex & 1995 & 557 & $40.6 \%$ & $26.9 \%$ & 8 & 0 \\
Legion & 1997 & 309 & $12.6 \%$ & $10.7 \%$ & 10 & 1 \\
Exodus & 1999 & 503 & $34.6 \%$ & $27.6 \%$ & 27 & 1 \\
\hline
\end{tabular}

According to the statistics in the core journals of architecture and security science, the number of literature about using the software of Building Exodus for simulation is over 40 since 2000. And many simulations of Building Exodus for emergency events are in the large public building. But Steve simulated the behaviors of the pedestrian in the Wangfujing Street by using Building Exodus in 2003, which build the foundation for the subsequent research of evacuation simulation in public 
space. Zhao Jiangping simulated regional emergency evacuation by using Building Exodus, which compensated for the gap of research for leakage accident in 2004 and also provided a method of regional evacuation simulation based on Building Exodus in the meantime. And this build the foundation for subsequent research of regional evacuation simulation. Consequently, Building Exodus is selected to be applied in the trial of evacuation simulation in the urban public space.

2.3 Construction of emergency evacuation model

This paper aims at constructing the emergency evacuation models based on the improved theory of Cellular Automaton(CA). The site is divided into some grids of $0.5 \mathrm{~m} * 0.5 \mathrm{~m}$ evenly, and the model determined the direction of movement by using the form of Moore. Building Exodus is applied inside the building traditionally, but this study provided a method based on Building Exodus which is now utilized in the urban public space.

\section{Test and analysis of evacuation simulation}

\subsection{The determination of evacuation site}

Harbin Children's Park is located in the commercial center of Nangang District, with a total area of 16.9 hectares. It is surrounded by four urban avenues. The northern gate of the park is located on the Dacheng Street which is the trunk road; the southern gate of the park is located on the Gogol Street which is the inferior road; the opposite side of western gate of the park is Hequ Street which is the ordinary road, and its surrounding roads including Xinyonghe Street, Renhe Street and Chongde Street are also ordinary roads.The oppostie side of eastern gate of the park is Majiagou River. The traffic condition of the surrounding areas of the park is convenient, and this area is gathered with lots of people.

Harbin Children's Park is determined to be the shelter for evacuation in Harbin urban green space system planning revision (2012-2020). Moreover, Harbin Children's Park is the only one determined shelter for evacuation within the Qiulin area of urban center in Harbin. According to Beijing city center earthquake and emergency shelters (outdoor) Plan and Urban Earthquake Disaster Prevention Planning Standards (GB50413-2007), the effective area of disaster prevention is half of the whole park, and the standard area is about $2-3 \mathrm{~m}^{2}$ per capita in the shelter area for evacuation. In this paper, the service radius for disaster prevention of Harbin Children's Park is set to 1000m in this evacuation simulation. And the sites within this scope are selected as evacuation areas. This model is used to guide personnel to evacuate in the selected area by the model established by Building Exodus for emergency evacuation.

\subsection{Evacuees setting}

In the process of the evacuation, the basic features and behavior patterns of evacuees is essential to the evacuation process. The basic features include gender, age, walking speed rates, etc. Behavior patterns contains the shortest route pattern, conformist mentality patterns, follow the guidance patterns and avoidance patterns. these kinds of data of evacuees can be set in Building Exodus.

\subsection{Evacuation model simulation}

The condition of simulation trial: 5,000 evacuees are in the determined sites; evacuees are distributed randomly on the pavements of the site; all of them are greatly familiar with four entrances of this park; the positions and walking speed rates of people in this park are set by Building Exodus randomly; evacuees can find the shortest evacuation routes to get to the entrances of the park. Evacuation simulation process are shown by the following figure. Figure 1 shows the evacuation scope, the pink area represents the safety area and the green points represents evacuees.

At the beginning of the evacuation, the walking speed rates of evacuees are less affected by personnel density, evacuees who are close to the park entrance can quickly enter the safety area. As time goes by, evacuees move to a nearby park entrance gradually, leading to evacuees density increases. Evacuees accumulation phenomenon in the entrance began to appear. With the number of people gathered at the entrance of the park continued to increase, the walking speed rates are limited in the entrance of the park. It began to appear congestion phenomenon that is not beneficial for evacuees to enter the safety area. Subsequently, the evacuees in the East Gate, South Gate and North 
Gate of the park have entered the safety area, but a large number of evacuees still gathered in the North Gate, waiting to enter. It shows that the evacuees in this entrance will take more time to be evacuated.

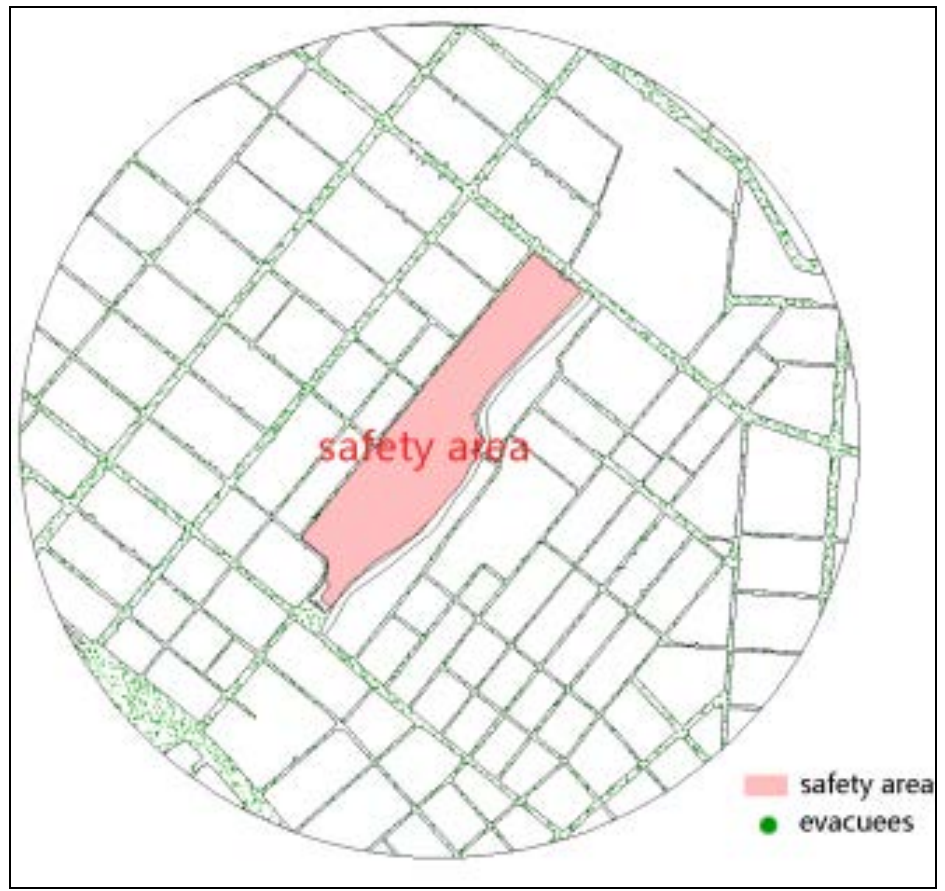

Fig. 1 The evacuation scope

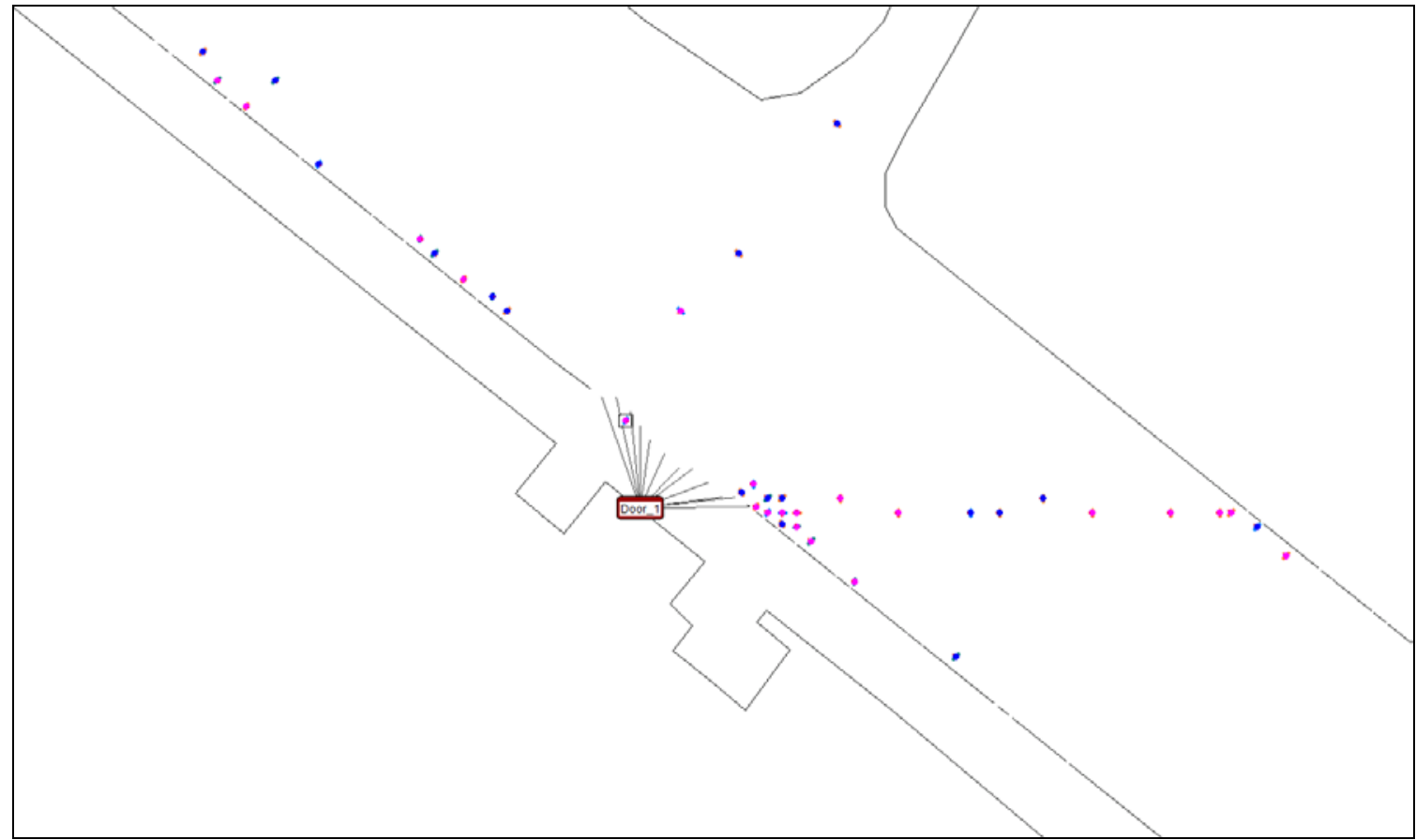

Fig. 2 Process of evacuation in 60s in Door 1 


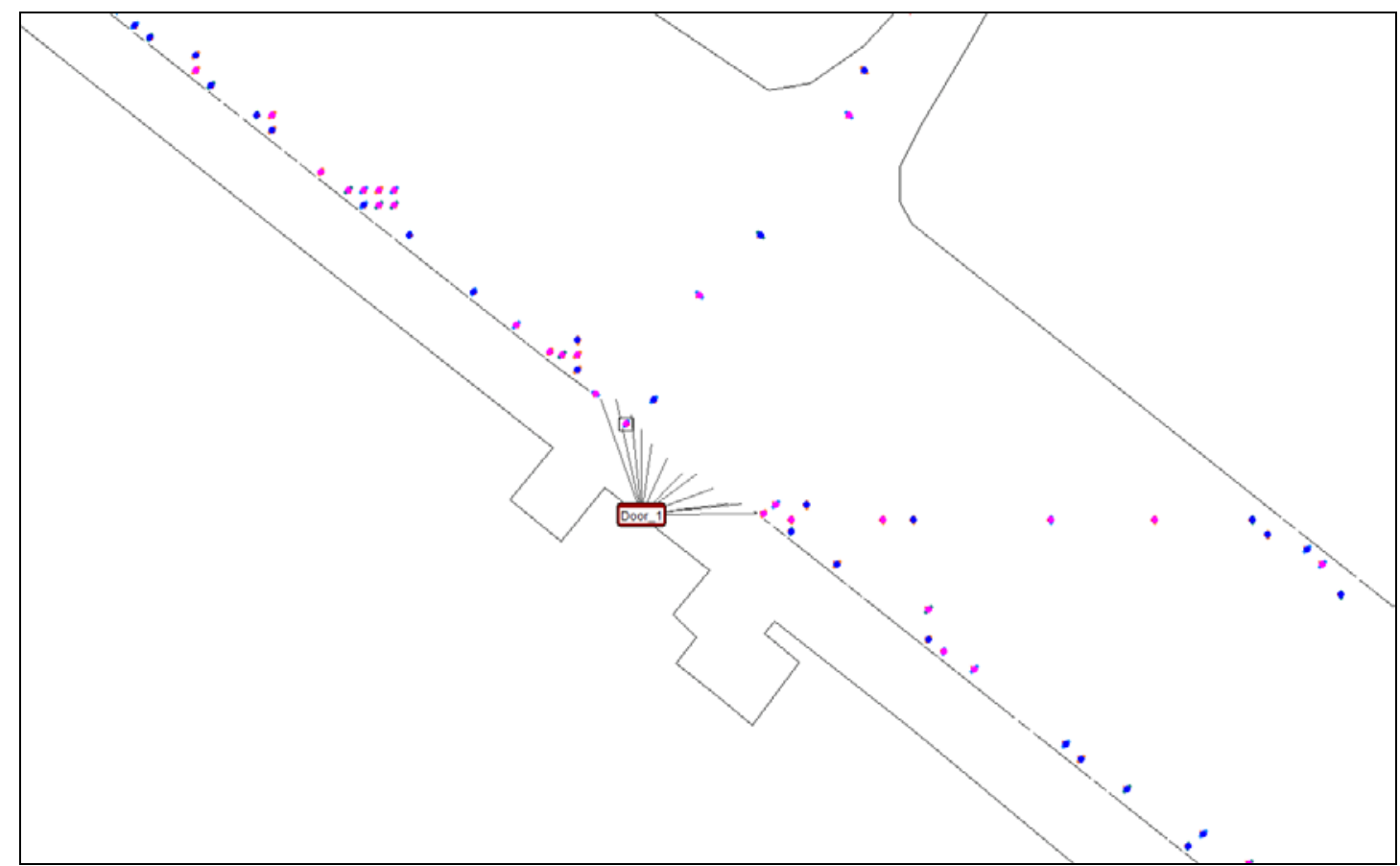

Fig. 3 Process of evacuation in 120s in Door 1

\section{Conclusion}

According to domestic and international research on the theory and software of emergency evacuation, this paper aims at creating an emergency evacuation model of urban public space based on the Building Exodus, and the improved theory of Cellular Automaton (CA) was employed as the theoretical basis of the model. Harbin Children's Park was selected as a shelter to simulate evacuation, which is based on virtual simulation technology. According to analysis of the results of simulation, some problems was founded during the process of evacuation in its surrounding area.

(1) Taking the traffic situation around the park into account, emergency evacuation signage related with the content of emergency evacuation and a special evacuation guide in the critical areas gathered with large quantities of residents are significant for further security.

(2) It can effectively avoid certain entrance congestion phenomenon by using the methods of areas division, and it can improve the evacuation in an efficient way.

(3) Usually, people should improve the awareness of preventing disasters by themselves and grasp the knowledge of the surrounding emergency evacuation sites and routes. These knowledge can assist each of them to reach safety spots quickly and improve the efficiency of evacuation in the whole area.

\section{Acknowledgements}

The Project Sponsored by the "National Natural Science Foundation of China" (No.51208135)," Heilongjiang Province Science Foundation for Youths （No.QC2011C098） and "the Fundamental Research Funds for the Central Universities” (Grant No.HIT.HSS.201133).

\section{References}

[1] Jing-hong Wang, Jin-hua Sunb. Principal Aspects regarding to the Emergency Evacuation of Large-scale Crowds: A Brief Review of Literatures until 2010. Procedia Engineering, 2014, 71(4): $1-6$

[2] Tian yuMin. Evacuation simulation to a library room of a university based on computer software building EXODUS. Applied Mechanics and Materials,2014, 651-653(1551-806X): 1576-1579 
[3] Feng Yao, Zhang Lusi. Understanding of Landscape Architecture Design in Japan Advanced Materials Research 2012(10):2840-2845

[4] Feng Yao, Zhang Lusi. Study on Application of Immersion VR System into Disaster Prevention Education- Take the study on facilities for Tokyo disaster prevention education as an example , Selected Papers IDRC on Risk Reduction and Disaster Management 2010(11) :78-85

[5] Tai Chengan, Lee Yunglung, Lin Chingyuan. Urban disaster prevention shelter location and evacuation behavior analysis. Journal of Asian Architecture and Building Engineering, 2010, 9(1): 215-220

[6] Chang Hsuehsheng, Liao ChinHsien. Planning emergency shelter locations based on evacuation behavior. Natural hazards(Dordrecht), 2015, 76(3): 1551-1571

[7] Wang Zhitao, Zhang Xiuyan, Wang Peng. Studied on establishing urban-rural disaster prevention system. Applied Mechanics and Materials, 2012, 166-169(1660-9336): 2676-2679

[8] Ayse I.parlak, James H.Lambert, Thomas M.Guterbock, Janet L.Clements. Population behavioral scenarios influencing radiological disaster preparedness and planning. Accident Analysis and Prevention, 2012, 48, 353-362

[9] Nabil, Ibrahim Mohareb. Emergency evacuation model: Accessibility as a starting point. Proceedings of the Institution of Civil Engineers, 2011, 164(4):215-224

[10] James H.Lambert, Ayse I.Parlak, Qian Zhou, John S.Miller. Understanding and managing disaster evacuation on a transportation network. Accident Analysis and Prevention, 2013, 50, 645-658 